\title{
Rheumatoid Arthritis-Associated Interstitial Lung Disease
}

\author{
The Relevance of Histopathologic and \\ Radiographic Pattern
}

\author{
Eunice J. Kim, MD; Harold R. Collard, MD, FCCP; \\ and Talmadge E. King Jr, MD, FCCP
}

\begin{abstract}
Interstitial lung disease (ILD) is a frequent extraarticular manifestation of rheumatoid arthritis (RA). While the nonspecific interstitial pneumonia pattern predominates in most forms of connective tissue-associated ILD, studies in patients with RA-associated ILD (RA-ILD) suggest that the usual interstitial pneumonia (UIP) pattern is more common in this patient population. High-resolution CT (HRCT) scans appear accurate in identifying UIP pattern in many patients with RA-ILD. Although the data are limited, UIP pattern appears to predict worse survival in RA-ILD patients. Larger, prospective, multicenter studies are needed to confirm this finding. We propose that the evaluation of patients with RA-ILD should focus on identifying those with UIP pattern on HRCT scans, as these patients are likely to carry a worse prognosis. In patients in whom the underlying pattern cannot be determined by HRCT scanning, surgical lung biopsy should be considered.

(CHEST 2009; 136:1397-1405)

Abbreviations: CTD $=$ connective tissue disease; CTD-ILD = connective tissue disease-associated interstitial lung disease; HRCT = high-resolution CT; IIP = idiopathic interstitial pneumonia; ILD = interstitial lung disease; IPF = idiopathic pulmonary fibrosis; NSIP = nonspecific interstitial pneumonia; PFT = pulmonary function test; RA = rheumatoid arthritis; RA-ILD = rheumatoid arthritis-associated interstitial lung disease; UIP = usual interstitial pneumonia
\end{abstract}

$\mathbf{R}$ heumatoid arthritis (RA) is a systemic inflammatory disease that affects approximately $1 \%$ of the population, ${ }^{1}$ and pulmonary involvement is common. Interstitial lung disease (ILD) is the primary pulmonary manifestation of RA, as it is for other connective tissue diseases (CTDs), such as scleroderma (systemic sclerosis), inflammatory myositis (polymyositis

Manuscript received February 18, 2009; revision accepted May 28, 2009.

Affiliations: From the Division of Pulmonary and Critical Care Medicine, Department of Medicine, University of California at San Francisco, San Francisco, CA.

Funding/Support: This work was supported by National Institutes of Health, National Heart, Lung, and Blood Institute grant HL086516.

Correspondence to: Eunice J. Kim, MD, 505 Parnassus Ave, Campus Box 0111, San Francisco, CA 94143; e-mail: ekim@ucsf.edu

(C) 2009 American College of Chest Physicians. Reproduction of this article is prohibited without written permission from the American College of Chest Physicians (www.chestjournal.org/site/ misc/reprints.xhtml).

DOI: 10.1378/chest.09-0444 and dermatomyositis), Sjögren syndrome, and undifferentiated CTD. ${ }^{2-7}$

RA-associated ILD (RA-ILD) is a source of substantial morbidity and mortality for affected patients. The histopathologic and radiographic appearance of RA-ILD is heterogeneous and primarily mimics the following two patterns seen in the idiopathic interstitial pneumonias (IIPs): usual interstitial pneumonia (UIP) and nonspecific interstitial pneumonia (NSIP) [Fig 1].

Distinguishing UIP from NSIP has important prognostic implications. Idiopathic UIP (ie, idiopathic pulmonary fibrosis [IPF]) has a uniformly poor prognosis and lacks an effective medical therapy; idiopathic NSIP has a better prognosis and often responds to anti-inflammatory therapy. Moreover, IPF, which is characterized by abnormal wound healing and abnormal epithelial cell function, is thought to have a distinct pathobiology from NSIP. Because of this, the diagnostic workup of patients with IIPs emphasizes the histopathologic and 

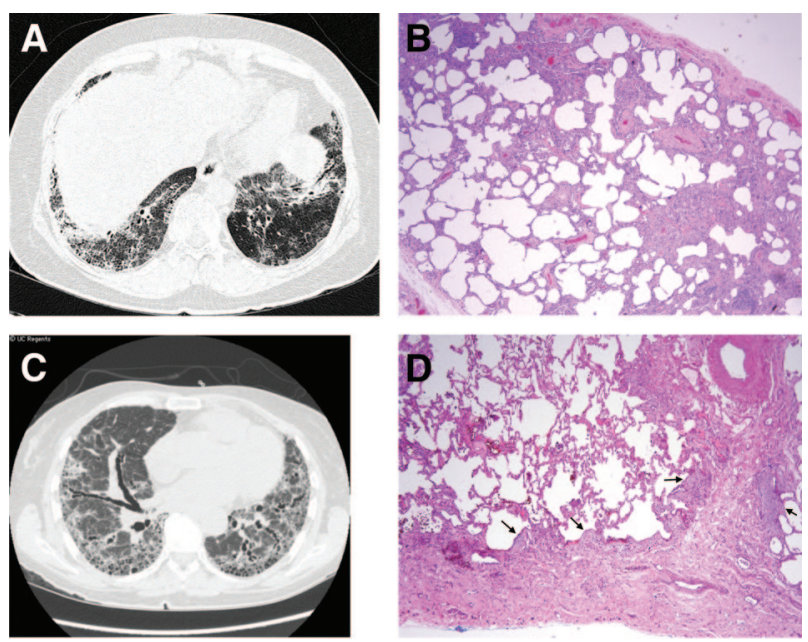

FIGURE 1. Radiographic and histopathologic appearances of NSIP and UIP. A: NSIP pattern; HRCT scan demonstrating the characteristic radiographic appearance of NSIP with bilateral, ground-glass opacities. B: NSIP pattern; lung biopsy specimen demonstrating a homogeneous cellular infiltrate typical of NSIP pattern. C: UIP pattern; HRCT scan demonstrating the characteristic radiographic appearance of a UIP pattern with bibasilar, reticular abnormalities, traction bronchiectasis, and honeycombing. D: UIP pattern; a lung biopsy specimen demonstrating areas of established fibrosis next to normal lung and focal fibroblastic activity (fibroblast foci) typical of UIP pattern (arrows). Although honeycombing is not seen on this view, the image demonstrates the classic "temporal heterogeneity" of UIP pattern.

radiographic identification of UIP. In many cases, radiographic imaging is sufficient, ${ }^{8}$ and surgical lung biopsy is required only for those patients in whom radiographic imaging is nondiagnostic. ${ }^{9}$

In contrast to the IIPs, histopathologic and radiographic appearance is rarely emphasized in the assessment of patients with RA-ILD. There are two primary explanations for this approach. First, although it is generally recognized that RA-ILD has a higher proportion of UIP compared with other forms of CTD-associated ILD (CTDILD), the prognostic value of this pattern is unclear. ${ }^{10,11}$ Second, the treatment of RA-ILD with anti-inflammatory agents, such as prednisone and immunomodulators (eg, azathioprine and cyclophosphamide), is generally recommended regardless of the underlying histopathologic pattern.

This review assesses the validity of these assumptions in RA-ILD patients by reviewing the data supporting or refuting each one. In particular, it focuses on the role that histopathologic and radiographic appearances play in determining the prognosis and management of RA-ILD. Further, it proposes a diagnostic approach to RA-ILD based on the available evidence. Finally, it identifies gaps in knowledge and suggests ways to address these gaps through future research.

\section{RA-ILD: EPIDEMIOLOGY AND CLINICAL Presentation}

The reported prevalence of ILD in patients with RA is highly variable and depends on the methods of detection (eg, high-resolution CT [HRCT] scan, chest radiograph, or pulmonary function testing) and the population selected for study (eg, symptomatic or asymptomatic, autopsy series). Studies ${ }^{12-19}$ have reported a prevalence as low as $4 \%$ and as high as $68 \%$. The majority of cases of RA-ILD occur in patients between the ages of 50 and 60 years. While several studies ${ }^{13,15-17,20}$ have reported smoking, male gender, and longstanding RA to be risk factors for the development of ILD, other reports ${ }^{13,14,16,17,19}$ have not shown any significant associations. In addition, genetic associations (human leukocyte antigen B40 and $\alpha_{1}$-antitrypsin) have been described. ${ }^{21,22}$

Though RA is often diagnosed before the detection of ILD due to the presence of articular disease, patients may present de novo with isolated pulmonary disease; in these cases, a high index of suspicion for RA-ILD is required to distinguish it from the IIPs. Similar to the IIPs, patients with RA and ILD most often present with chronic symptoms of dyspnea and cough. A physical examination may reveal inspiratory crackles, and pulmonary function test (PFT) results demonstrate restrictive physiology often with a reduced diffusing capacity. HRCT scanning is generally sufficient to confirm the diagnosis of ILD, although in a minority of cases, surgical lung biopsy may be required.

\section{RA-ILD: HistopatholOGY}

Although a broad range of histopathologic patterns has been associated with many of the CTDILDs, RA-ILD appears to be one of the most diverse (Fig 2). The predominant histopathologic pattern in patients with scleroderma is NSIP. ${ }^{10}$ Limited studies in patients with other forms of CTD-ILD (eg, polymyositis, Sjögren syndrome, and undifferentiated CTD) have also shown a predominance of NSIP pattern on surgical lung biopsy specimens..$^{5,23-25}$ In contrast, the currently available data show that, among RA-ILD patients, there is a higher proportion of patients with UIP pattern ${ }^{26}$ when compared with patients with other CTDs. Lee et $\mathrm{al}^{26}$ found UIP to be the most common histopathologic pattern in RA-ILD patients $(56 \%)$. This was followed by NSIP $(33 \%)$ and organizing pneumonia (11\%). 


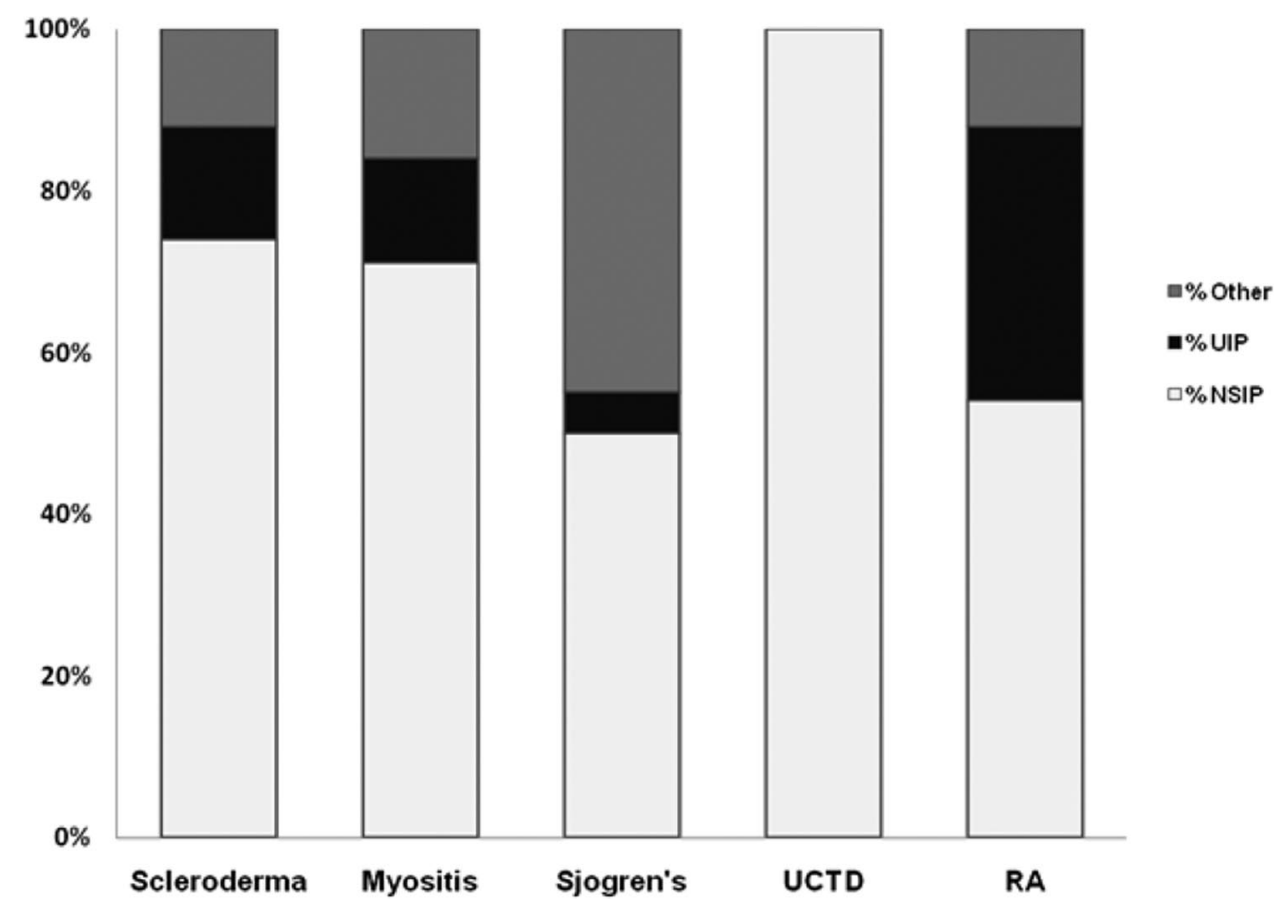

FIGURE 2. Proportions of histopathologic UIP and NSIP in patients with CTD-ILD. Combined data from published case series of patients with various forms of CTD-ILD demonstrate that UIP pattern is more common in patients with RA-ILD. The following are data compiled and aggregated from multiple studies: scleroderma ${ }^{10,46,47}$; myositis ${ }^{23,48-50}$; Sjögren syndrome ${ }^{24,49,51}$; undifferentiated CTD ${ }^{5}$; and RA. $26,27,31,49,52$

\section{RA-ILD: RADIOGRAPHIC-HISTOPATHOLOGIC CORRELATION}

The following four major radiographic patterns have been identified in patients with RA-ILD: a UIP-like pattern with bilateral subpleural reticulation with or without honeycombing; NSIP-like pattern with predominant ground-glass opacities; an inflammatory airway disease pattern with centrilobular branching lines with or without bronchial dilatation; and an organizing pneumonia-like pattern with patchy areas of consolidation. ${ }^{27}$

There are data demonstrating excellent correlation between the histopathologic pattern found on surgical lung biopsy and the radiographic pattern found on HRCT scans in patients with IPF. ${ }^{8,28}$ The correlation between histopathologic and radiographic patterns in RA-ILD patients has not been as rigorously studied, but it appears that the same correlation is present (Table 1). Akira et al ${ }^{29}$ published an article showing HRCT scan findings for 29 patients with RA-ILD. Although these investigators did not specifically use the terms "UIP" or "NSIP" to describe the radiographic appearance, 19 patients had reticulation with and without honeycombing; these appearances likely represent UIP pattern. Lung biopsy specimens were available in 14 of these 19 patients, and all patients showed UIP pattern. Tanaka et $\mathrm{al}^{27}$ demonstrated that $41 \%$ of a retrospective RA-ILD cohort had UIP pattern seen on HRCT scans, with $30 \%$ showing a fibrotic NSIP pattern. Of the 26 patients with UIP pattern seen on HRCT scan, only 4 patients underwent lung biopsies; 2 patients had UIP, and 2 patients had fibrotic NSIP. Of the eight patients with NSIP seen on HRCT scans who underwent lung biopsy, seven patients had NSIP on histopathology.

In 2005, Lee et $\mathrm{a}^{26}$ examined data from 18 patients with RA-ILD who had undergone surgical lung biopsy. Ten patients had UIP on histopathology, and 6 patients had fibrotic NSIP. Among the patients with UIP pattern seen on the lung biopsy specimen, nine patients had HRCT scans with reticulation and honeycombing, and one patient demonstrated reticulation and ground-glass opacities. Of the patients with NSIP pattern seen on a lung biopsy specimen, three patients had reticulation and ground-glass opacities, and the other three patients had predominant ground-glass opacity seen on HRCT scan.

These data, although limited, suggest that HRCT scanning is reasonably specific for the presence of UIP pattern seen on surgical lung biopsy specimens in patients with RA-ILD. These findings need to be confirmed in larger studies. 


\begin{tabular}{|c|c|c|c|}
\hline \multirow[b]{2}{*}{ Study } & \multicolumn{3}{|c|}{ Histopathology, No. } \\
\hline & UIP & NSIP & Other \\
\hline \multicolumn{4}{|c|}{$\begin{array}{l}\text { UIP pattern on HRCT scan (reticulation with/without } \\
\text { honeycombing) }[\mathrm{n}=36]\end{array}$} \\
\hline Akira et $\mathrm{al}^{29}$ & 14 & 0 & \\
\hline Lee et $\mathrm{al}^{26}$ & 9 & 0 & \\
\hline Tanaka et $\mathrm{al}^{27}$ & 2 & 2 & \\
\hline Yoshinouchi et $\mathrm{al}^{52}$ & 7 & 2 & \\
\hline Total & $32(89 \%)$ & $4(11 \%)$ & \\
\hline \multicolumn{4}{|c|}{$\begin{array}{l}\text { Indeterminate pattern on HRCT scan (reticulation plus ground- } \\
\text { glass opacity) }[\mathrm{n}=5]\end{array}$} \\
\hline Akira et $\mathrm{al}^{29}$ & 0 & 0 & \\
\hline Lee et $\mathrm{al}^{26}$ & 1 & 3 & \\
\hline Tanaka et $\mathrm{al}^{27}$ & 0 & 0 & \\
\hline Yoshinouchi et $\mathrm{al}^{52}$ & 1 & 0 & \\
\hline Total & $2(40 \%)$ & $3(60 \%)$ & \\
\hline \multicolumn{4}{|c|}{ NSIP pattern on HRCT scan (ground-glass predominant) $[\mathrm{n}=15]$} \\
\hline Akira et $\mathrm{al}^{29}$ & & 0 & 0 \\
\hline Lee et $\mathrm{al}^{26}$ & & 3 & 0 \\
\hline Tanaka et $\mathrm{al}^{27}$ & & 7 & $1^{*}$ \\
\hline Yoshinouchi et $\mathrm{al}^{52}$ & & 4 & 0 \\
\hline Total & & $14(93 \%)$ & $1(7 \%)$ \\
\hline
\end{tabular}

\section{Histopathologic Pattern in RA-ILD: Does IT MATTER?}

Pathophysiologic Implications

Few studies have assessed whether histopathologic pattern suggests a distinct pathophysiology in RA-ILD patients. Gochuico et al ${ }^{17}$ compared patients with RA who had HRCT scan findings consistent with NSIP pattern $(\mathrm{n}=21)$ with those who had findings consistent with UIP pattern $(\mathrm{n}=10)$. They showed that patients with RA and NSIP pattern on HRCT scans had higher concentrations of platelet-derived growth factors $\mathrm{AB}$ and $B B$, interferon- $\gamma$, and transforming growth factor $\beta_{2}$ in BAL fluid compared with those patients with RA and UIP pattern. Patients with NSIP also had a longer duration of articular symptoms. Based on these findings, the authors suggest that the pathophysiology of NSIP and UIP pattern in patients with RA-ILD may be different. Biederer et al ${ }^{30}$ reported that patients with RA-ILD with a predominantly ground-glass pattern seen on HRCT scans had a shorter mean $( \pm S D)$ duration of RA than those patients with a reticular pattern (63 \pm 38 months vs $133 \pm 112$ months, respectively; $\mathrm{p}<0.01)$. Although the authors did not specifically distinguish between UIP and NSIP patterns, the ground-glass pattern described most likely represented NSIP.
Serologic and lymphocyte profiling have shown no clear evidence of distinction between patients with RA-ILD and UIP or NSIP pattern. Although one study ${ }^{31}$ did show a trend toward lower anticyclic citrullinated peptide antibody levels in patients with RA-ILD and UIP pattern, there have been no convincing data reported that citrullination is significantly associated with either pattern. ${ }^{32}$ Studies $^{33-35}$ looking at CD20+ B lymphocytes, CD4+ T lymphocytes, and mast cells in lung biopsy specimens from patients with RA-ILD did not show significant differences between UIP and NSIP patterns. Although several studies ${ }^{36-38}$ have established the importance of genetic susceptibility in the development of RA, there are no data describing its association with UIP pattern.

The radiologic and histopathologic patterns may be influenced by cigarette smoking. Biederer et $\mathrm{al}^{30}$ reported a trend toward a higher number of packyears of smoking in those with pure reticular opacity vs those with predominant ground-glass opacity on HRCT scans, suggesting that smoking could be associated with UIP over NSIP. In addition, Lee et $\mathrm{a}^{26}$ reported that all the patients with RA-ILD and histopathologic UIP pattern were smokers, while those with NSIP pattern were nonsmokers.

Thus, studies published to date have been limited and discordant. Until more data become available, 
Table 2-Outcomes Based on Histopathologic Pattern in RA-ILD

\begin{tabular}{|c|c|c|c|}
\hline Study & Patients, No. & Survival & Comments \\
\hline \multirow[t]{2}{*}{ Park et $\mathrm{al}^{40}$} & 18 UIP & $\begin{array}{l}\text { Mean survival time, } 96 \text { mo (hazard ratio, } \\
19 ; \mathrm{p}=0.08 \text { ) }\end{array}$ & \\
\hline & $10 \mathrm{NSIP}$ & Mean survival time, 124 mo & \\
\hline \multirow[t]{2}{*}{ Yoshinouchi et al $^{52}$} & 9 UIP & Alive in follow-up period, 7 patients $(77 \%)$ & $\begin{array}{l}\text { Two patients with UIP/NSIP pattern on pathology included } \\
\text { in UIP gruop }\end{array}$ \\
\hline & $7 \mathrm{NSIP}$ & Alive in follow-up period, 4 patients $(47 \%)$ & $\begin{array}{l}\text { Two of } 3 \text { deaths in NSIP group were nonrespiratory } \\
\text { (arrhythmia and GI bleed) }\end{array}$ \\
\hline Hakala et $\mathrm{al}^{54}$ & 2 UIP* & Deaths, 2 patients & \\
\hline \multirow{3}{*}{ Yousem et $\mathrm{al}^{55}$} & 5 UIP & Deaths 4 patients & One death in the UUP oroun was nonresniratory \\
\hline & 5 CIP & Deaths, 1 patient & One deatn in the Uir group was nonrespiratory \\
\hline & 30 other & & CIP likely represents NSIP \\
\hline
\end{tabular}

$\mathrm{CIP}=$ cellular interstitial pneumonia.

*Both patients had honeycombing.

the relevance of histopathologic pattern to pathogenesis in RA-ILD patients will remain unknown.

\section{Prognostic Implications}

RA-ILD associated with UIP pattern appears to have an increased risk of disease progression and death (Table 2). A prospective study ${ }^{39}$ of patients with RA-ILD followed up for 24 months demonstrated that two of the three patients with a predominant ground-glass pattern on HRCT scans had spontaneous improvement compared with none in the group with a reticular pattern. While this study did not characterize patients as having either UIP or NSIP pattern on HRCT scans, a predominant ground-glass pattern is more likely to be associated with NSIP. A study ${ }^{40}$ of 28 patients with RA-ILD found a strong trend toward worse survival in patients with UIP compared with patients with NSIP (hazard ratio, 18.952; $\mathrm{p}=0.08$ ).

Acute worsening of disease has been reported in RA-ILD patients, ${ }^{41}$ and appears to occur primarily in those patients with UIP pattern. ${ }^{29,39}$ In a study of a large cohort of 93 subjects with CTD-ILD, Park et $\mathrm{al}^{42}$ reported a 1 -year incidence of acute worsening of $3.3 \%$ (four subjects). Three of these four patients had RA with proven UIP seen on a lung biopsy specimen.

There are limited data regarding the response to therapy based on histopathologic pattern in RA-ILD patients. In one recent narrative review, ${ }^{43}$ the authors concluded that, based on their own experiences, patients with RA-ILD and UIP pattern are less likely to respond to therapy with corticosteroids than patients with RA-ILD and NSIP or organizing pneumonia pattern. It remains unclear, however, if the therapeutic implications of UIP pattern in patients with RA-ILD are similar to those of UIP pattern in patients with IPF.

\section{COMPARING UIP IN RA-ILD WITH IPF}

There are limited data directly comparing patients with RA-ILD and UIP pattern with patients with IPF. The lung histopathology of UIP in patients with CTD has been shown ${ }^{44}$ to have fewer fibroblast foci when compared with patients with IPF. In addition, the number of CD4+ lymphocytes appears to be increased in lung specimens from patients with RA-ILD and UIP pattern vs patients with IPF. ${ }^{35}$ As a group, patients with RA-ILD are thought to have a better prognosis than those with IPF. In a prospective double cohort study of 18 patients with RA-ILD and 18 patients with IPF, Rajasekaran et al ${ }^{45}$ reported an improved survival time in patients with RA-ILD (median survival rate: 60 months vs 27 months, respectively). This study, however, did not distinguish between UIP and NSIP patterns in its RA-ILD cohort.

The most relevant data come from Park et $\mathrm{al}^{40}$ who compared survival times in 28 patients with RA-ILD with those in 203 patients with IPF (Fig 3). On univariate analysis, survival was worse in the group of patients with RA-ILD and UIP pattern $(n=10)$ when compared with the population of patients with CTD and NSIP $(p=0.04)$. Although this comparison lost statistical significance with multivariate adjustment $(p=0.07)$, the small size of the population of patients with RA-ILD and UIP pattern makes such an analysis underpowered. There was no significant difference in survival time between the patients with RA-ILD and UIP pattern and the patients with IPF.

\section{Diagnostic and Management Approach TO RA-ILD}

Based on the evidence available to date, UIP pattern in RA-ILD patients appears to be common, 


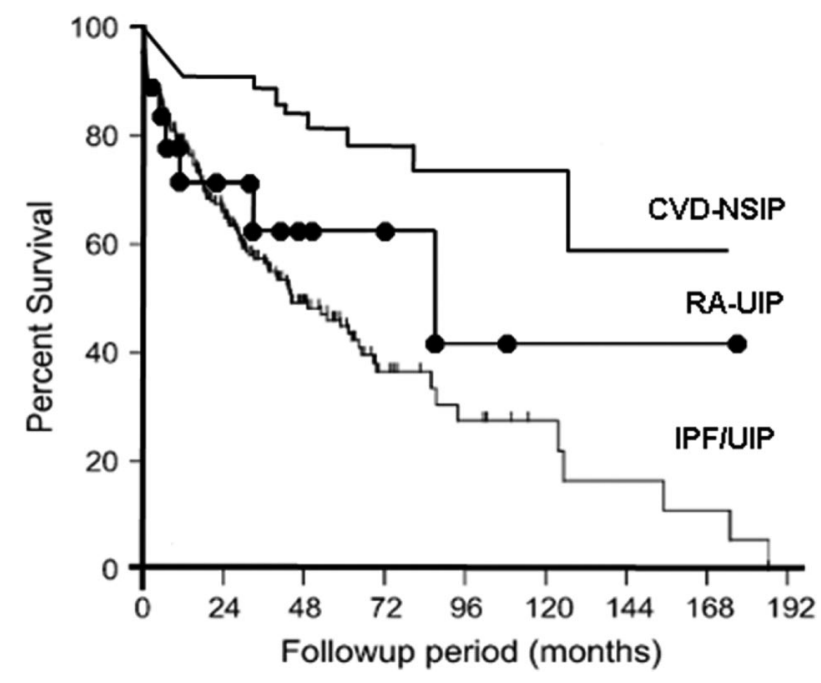

FiguRE 3. Survival data from a cohort of 28 patients with RA-ILD were compared with data from other patients with CTD-ILD and IPF. Patients with RA-ILD and UIP pattern (RA-UIP) had a worse survival time than patients with CTD-ILD and NSIP pattern (CVD-NSIP; $\mathrm{p}=0.04$ ), and were no different from patients with IPF. CVD = collagen vascular disease. Redrawn from Park et $\mathrm{al}^{40}$ with permission.

identifiable by HRCT scanning, and predictive of poor survival. With this in mind, we propose the following approach to patients with RA-ILD (Fig 4). Given the possibility of subclinical disease, the clinician should have a low threshold for evaluating patients with RA for ILD. Although we do not recommend the routine screening of patients with RA with HRCT scans and PFTs, a future study of the cost-effectiveness of this approach is warranted. Each of these recommendations should be reviewed as additional data become available.

- All patients with RA should undergo annual screening for ILD. The clinician should evaluate for the presence of cough, dyspnea, and crackles on pulmonary auscultation. In addition, clubbing is highly suggestive of pulmonary involvement.

- A chest radiograph should be obtained at the time RA is diagnosed, then at intervals (eg, every other year) thereafter. In patients with longstanding RA ( $>10$ years), an annual chest radiograph should be considered. The loss of lung volumes or interstitial markings should prompt additional evaluation.

- When ILD is suspected, a careful exposure history (from occupational and environmental exposures, and from medication) should be conducted to evaluate for potential alternative causes. Concomitant secondary Sjögren syndrome should also be considered, and serologic evaluation for the presence of autoantibodies (anti-SS-A/Ro and anti-SS$\mathrm{B} / \mathrm{La})$ should be performed.

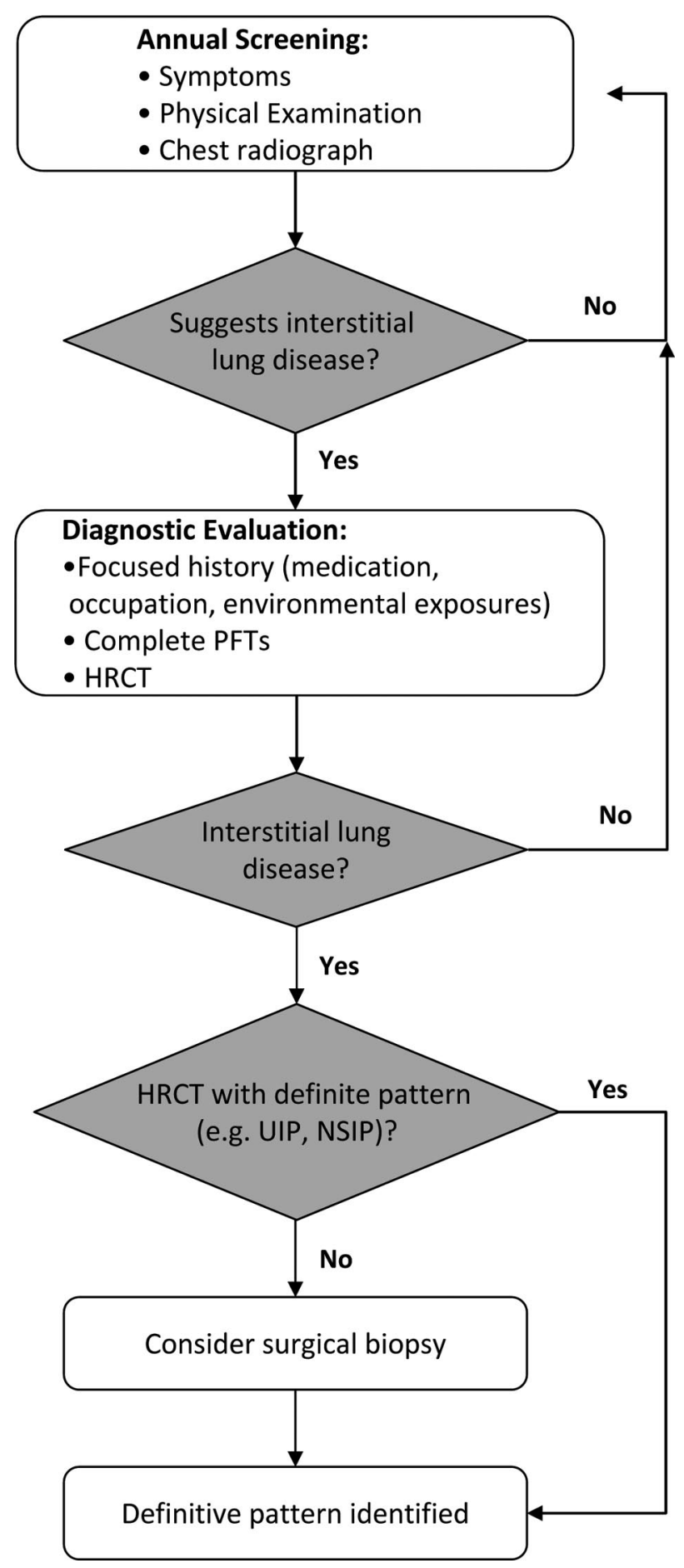

Figure 4. Proposed algorithm for the evaluation and management of suspected patients with RA-ILD. Patients with suspected RA-ILD should be screened annually for the presence of ILD with a history and a physical examination. In suspected cases of ILD, additional testing with PFTs and HRCT scanning is indicated. In the absence of a definitive radiographic pattern, surgical lung biopsy should be considered.

- All patients with RA and suspected ILD should undergo full PFTs (including spirometry, lung volumes, and diffusing capacity of the lung for carbon monoxide). 
- HRCT scans should be obtained in all patients with suspected ILD. There are no convincing data on the sensitivity of HRCT scanning for RA-ILD, but it is likely that early disease may only occasionally be missed. ${ }^{16}$ In patients with HRCT scan findings consistent with UIP pattern, the diagnosis of RA-ILD with UIP pattern can be made confidently. Similarly, the HRCT scan appearance of isolated ground-glass opacity without honeycombing or reticulation appears to correlate well with histopathologic NSIP. In indeterminate cases, surgical lung biopsy should be considered. The risks of surgery should be weighed on a case-by-case basis.

- Patients with RA-ILD and NSIP pattern should be treated aggressively with pharmacologic therapy.

- Patients with RA-ILD and UIP pattern should be counseled as to their worse prognosis and referred for lung transplantation evaluation if considered a reasonable candidate. The role of pharmacologic therapy in this setting is unknown and should be the focus of future study.

\section{GAPS IN OUR KNOWLEDGE}

Some may continue to question whether the existing data are sufficient to make such recommendations. It can also be argued that if we are going to treat these patients with the same agents regardless of histopathologic and radiographic pattern, does prognostic information alone warrant the risk of surgical biopsy? These are legitimate questions that individual clinicians and patients must answer for themselves. We certainly agree that more information is needed, and this will come only from welldesigned clinical studies.

Studying RA-ILD is challenging given the small numbers of affected patients. We believe that to adequately study this condition, a large, prospective, multicenter, longitudinal cohort of carefully described patients with RA-ILD must be developed. With such a collaborative effort, we could begin to definitively answer the following questions:

- Is UIP the predominant pattern in patients with RA-ILD?

- What factors (eg, genetics and smoking) contribute to the development of UIP pattern?

- Do histopathologic and radiographic patterns reliably provide prognostic information in terms of survival and treatment response?

- Do UIP and NSIP patterns in patients with RAILD have distinct pathophysiologies, and do they respond differently to medical therapy?

- Do IPF and RA-ILD with UIP share a similar pathophysiology, clinical course, and prognosis?
We believe the existing data from studies of RA-ILD suggest that UIP pattern is common and relevant to the management of these patients. Future research needs to focus closely on the questions raised above. Answering them will improve our understanding of RA-ILD, better inform our diagnostic approach, and provide insight into how to better the lives of these patients.

\section{ACKNOWLEDGMENTS}

Financial/nonfinancial disclosures: The authors have reported to the ACCP that no significant conflicts of interest exist with any companies/organizations whose products or services may be discussed in this article.

Other contributions: We thank Kirk Jones, MD, for providing the histopathologic images in Figure 1.

\section{REFERENCES}

1 Gabriel SE. The epidemiology of rheumatoid arthritis. Rheum Dis Clin North Am 2001; 27:269-281

2 Bodolay E, Szekanecz Z, Devenyi K, et al. Evaluation of interstitial lung disease in mixed connective tissue disease (MCTD). Rheumatology (Oxford) 2005; 44:656-661

3 Fathi M, Vikgren J, Boijsen M, et al. Interstitial lung disease in polymyositis and dermatomyositis: longitudinal evaluation by pulmonary function and radiology. Arthritis Rheum 2008; 59:677-685

4 Hayashi S, Tanaka M, Kobayashi H, et al. High-resolution computed tomography characterization of interstitial lung diseases in polymyositis/dermatomyositis. J Rheumatol 2008; 35:260-269

5 Kinder BW, Collard HR, Koth L, et al. Idiopathic nonspecific interstitial pneumonia: lung manifestation of undifferentiated connective tissue disease? Am J Respir Crit Care Med 2007; 176:691-697

6 Steen VD, Conte C, Owens GR, et al. Severe restrictive lung disease in systemic sclerosis. Arthritis Rheum 1994; 37:12831289

7 Uffmann M, Kiener HP, Bankier AA, et al. Lung manifestation in asymptomatic patients with primary Sjögren syndrome: assessment with high resolution CT and pulmonary function tests. J Thorac Imaging 2001; 16:282-289

8 Hunninghake GW, Zimmerman MB, Schwartz DA, et al. Utility of a lung biopsy for the diagnosis of idiopathic pulmonary fibrosis. Am J Respir Crit Care Med 2001; 164 : 193-196

9 American Thoracic Society, European Respiratory Society. American Thoracic Society/European Respiratory Society International Multidisciplinary Consensus Classification of the Idiopathic Interstitial Pneumonias: this joint statement of the American Thoracic Society (ATS), and the European Respiratory Society (ERS) was adopted by the ATS board of directors, June 2001 and by the ERS Executive Committee, June 2001. Am J Respir Crit Care Med 2002; 165:277-304

10 Bouros D, Wells AU, Nicholson AG, et al. Histopathologic subsets of fibrosing alveolitis in patients with systemic sclerosis and their relationship to outcome. Am J Respir Crit Care Med 2002; 165:1581-1586

11 Ryu JH, Bongartz T, Matteson EL. Interstitial lung disease in connective tissue diseases: what are the important questions? Arthritis Rheum 2005; 53:488-490 
12 Carmona L, Gonzalez-Alvaro I, Balsa A, et al. Rheumatoid arthritis in Spain: occurrence of extra-articular manifestations and estimates of disease severity. Ann Rheum Dis 2003; 62:897-900

13 Bilgici A, Ulusoy H, Kuru O, et al. Pulmonary involvement in rheumatoid arthritis. Rheumatol Int 2005; 25:429-435

14 Dawson JK, Fewins HE, Desmond J, et al. Fibrosing alveolitis in patients with rheumatoid arthritis as assessed by high resolution computed tomography, chest radiography, and pulmonary function tests. Thorax 2001; 56:622-627

15 Demir R, Bodur H, Tokoglu F, et al. High resolution computed tomography of the lungs in patients with rheumatoid arthritis. Rheumatol Int 1999; 19:19-22

16 Gabbay E, Tarala R, Will R, et al. Interstitial lung disease in recent onset rheumatoid arthritis. Am J Respir Crit Care Med 1997; 156:528-535

17 Gochuico BR, Avila NA, Chow CK, et al. Progressive preclinical interstitial lung disease in rheumatoid arthritis. Arch Intern Med 2008; 168:159-166

18 Hassan WU, Keaney NP, Holland CD, et al. High resolution computed tomography of the lung in lifelong non-smoking patients with rheumatoid arthritis. Ann Rheum Dis 1995; 54:308-310

19 Mori S, Cho I, Koga Y, et al. Comparison of pulmonary abnormalities on high-resolution computed tomography in patients with early versus longstanding rheumatoid arthritis. J Rheumatol 2008; 35:1513-1521

20 Saag KG, Kolluri S, Koehnke RK, et al. Rheumatoid arthritis lung disease: determinants of radiographic and physiologic abnormalities. Arthritis Rheum 1996; 39:1711-1719

21 Charles PJ, Sweatman MC, Markwick JR, et al. HLA-B40: a marker for susceptibility to lung disease in rheumatoid arthritis. Dis Markers 1991; 9:97-101

22 Michalski JP, McCombs CC, Scopelitis E, et al. Alpha 1-antitrypsin phenotypes, including $\mathrm{M}$ subtypes, in pulmonary disease associated with rheumatoid arthritis and systemic sclerosis. Arthritis Rheum 1986; 29:586-591

23 Douglas WW, Tazelaar HD, Hartman TE, et al. Polymyositisdermatomyositis-associated interstitial lung disease. Am J Respir Crit Care Med 2001; 164:1182-1185

24 Ito I, Nagai S, Kitaichi M, et al. Pulmonary manifestations of primary Sjögren's syndrome: a clinical, radiologic, and pathologic study. Am J Respir Crit Care Med 2005; 171:632-638

25 Nakamura Y, Chida K, Suda T, et al. Nonspecific interstitial pneumonia in collagen vascular diseases: comparison of the clinical characteristics and prognostic significance with usual interstitial pneumonia. Sarcoidosis Vasc Diffuse Lung Dis 2003; 20:235-241

26 Lee HK, Kim DS, Yoo B, et al. Histopathologic pattern and clinical features of rheumatoid arthritis-associated interstitial lung disease. Chest 2005; 127:2019-2027

27 Tanaka N, Kim JS, Newell JD, et al. Rheumatoid arthritisrelated lung diseases: CT findings. Radiology 2004; 232:81-91

28 Raghu G, Mageto YN, Lockhart D, et al. The accuracy of the clinical diagnosis of new-onset idiopathic pulmonary fibrosis and other interstitial lung disease: a prospective study. Chest 1999; 116:1168-1174

29 Akira M, Sakatani M, Hara H. Thin-section CT findings in rheumatoid arthritis-associated lung disease: CT patterns and their courses. J Comput Assist Tomogr 1999; 23:941-948

30 Biederer J, Schnabel A, Muhle C, et al. Correlation between HRCT findings, pulmonary function tests and bronchoalveolar lavage cytology in interstitial lung disease associated with rheumatoid arthritis. Eur Radiol 2004; 14:272-280

31 Inui N, Enomoto N, Suda T, et al. Anti-cyclic citrullinated peptide antibodies in lung diseases associated with rheumatoid arthritis. Clin Biochem 2008; 41:1074-1077
32 Bongartz T, Cantaert T, Atkins SR, et al. Citrullination in extra-articular manifestations of rheumatoid arthritis. Rheumatology (Oxford) 2007; 46:70-75

33 Atkins SR, Matteson EL, Myers JL, et al. Morphological and quantitative assessment of mast cells in rheumatoid arthritis associated non-specific interstitial pneumonia and usual interstitial pneumonia. Ann Rheum Dis 2006; 65:677-680

34 Atkins SR, Turesson C, Myers JL, et al. Morphologic and quantitative assessment of CD20 + B cell infiltrates in rheumatoid arthritis-associated nonspecific interstitial pneumonia and usual interstitial pneumonia. Arthritis Rheum 2006; 54 : 635-641

35 Turesson C, Matteson EL, Colby TV, et al. Increased CD4+ $\mathrm{T}$ cell infiltrates in rheumatoid arthritis-associated interstitial pneumonitis compared with idiopathic interstitial pneumonitis. Arthritis Rheum 2005; 52:73-79

36 Begovich AB, Carlton VE, Honigberg LA, et al. A missense single-nucleotide polymorphism in a gene encoding a protein tyrosine phosphatase (PTPN22) is associated with rheumatoid arthritis. Am J Hum Genet 2004; 75:330-337

37 Remmers EF, Plenge RM, Lee AT, et al. STAT4 and the risk of rheumatoid arthritis and systemic lupus erythematosus. N Engl J Med 2007; 357:977-986

38 Wordsworth BP, Lanchbury JS, Sakkas LI, et al. HLA-DR4 subtype frequencies in rheumatoid arthritis indicate that DRB1 is the major susceptibility locus within the HLA class II region. Proc Natl Acad Sci U S A 1989; 86:10049-10053

39 Dawson JK, Fewins HE, Desmond J, et al. Predictors of progression of HRCT diagnosed fibrosing alveolitis in patients with rheumatoid arthritis. Ann Rheum Dis 2002; 61:517-521

40 Park JH, Kim DS, Park IN, et al. Prognosis of fibrotic interstitial pneumonia: idiopathic versus collagen vascular disease-related subtypes. Am J Respir Crit Care Med 2007; 175:705-711

41 Pratt DS, Schwartz MI, May JJ, et al. Rapidly fatal pulmonary fibrosis: the accelerated variant of interstitial pneumonitis. Thorax 1979; 34:587-593

42 Park IN, Kim DS, Shim TS, et al. Acute exacerbation of interstitial pneumonia other than idiopathic pulmonary fibrosis. Chest 2007; 132:214-220

43 Nannini C, Ryu JH, Matteson EL. Lung disease in rheumatoid arthritis. Curr Opin Rheumatol 2008; 20:340-346

44 Flaherty KR, Colby TV, Travis WD, et al. Fibroblastic foci in usual interstitial pneumonia: idiopathic versus collagen vascular disease. Am J Respir Crit Care Med 2003; 167:14101415

45 Rajasekaran A, Shovlin D, Saravanan V, et al. Interstitial lung disease in patients with rheumatoid arthritis: comparison with cryptogenic fibrosing alveolitis over 5 years. J Rheumatol 2006; 33:1250-1253

46 Fujita J, Yoshinouchi T, Ohtsuki Y, et al. Non-specific interstitial pneumonia as pulmonary involvement of systemic sclerosis. Ann Rheum Dis 2001; 60:281-283

47 Kim DS, Yoo B, Lee JS, et al. The major histopathologic pattern of pulmonary fibrosis in scleroderma is nonspecific interstitial pneumonia. Sarcoidosis Vasc Diffuse Lung Dis 2002; 19:121-127

48 Cottin V, Thivolet-Bejui F, Reynaud-Gaubert M, et al. Interstitial lung disease in amyopathic dermatomyositis, dermatomyositis and polymyositis. Eur Respir J 2003; 22:245250

49 Tansey D, Wells AU, Colby TV, et al. Variations in histological patterns of interstitial pneumonia between connective tissue disorders and their relationship to prognosis. Histopathology 2004; 44:585-596

50 Won Huh J, Soon Kim D, Keun Lee C, et al. Two distinct 
clinical types of interstitial lung disease associated with polymyositis-dermatomyositis. Respir Med 2007; 101:17611769

51 Parambil JG, Myers JL, Lindell RM, et al. Interstitial lung disease in primary Sjögren syndrome. Chest 2006; 130:14891495

52 Yoshinouchi T, Ohtsuki Y, Fujita J, et al. Nonspecific interstitial pneumonia pattern as pulmonary involvement of rheumatoid arthritis. Rheumatol Int 2005; 26:121-125
53 Flaherty KR, Travis WD, Colby TV, et al. Histopathologic variability in usual and nonspecific interstitial pneumonias. Am J Respir Crit Care Med 2001; 164:1722-1727

54 Hakala M, Paakko P, Huhti E, et al. Open lung biopsy of patients with rheumatoid arthritis. Clin Rheumatol 1990; 9:452-460

55 Yousem SA, Colby TV, Carrington CB. Lung biopsy in rheumatoid arthritis. Am Rev Respir Dis 1985; 131:770777 